\title{
Representações sociais da diferença: sexualidade e deficiência mental
}

ANA TERESA A. VENANCIO*

\begin{abstract}
GIAMI, Alain.
$O$ anjo e a fera: sexualidade, deficiência mental e instituição. São Paulo: Casa do Psicólogo, 2004.
\end{abstract}

$O$ anjo e a fera: sexualidade, deficiência mental e instituição divulga os estudos de Alain Giami a respeito das representações sobre a sexualidade dos deficientes mentais, reunindo-os pela primeira vez aos resultados da pesquisa sobre o tema, realizada na França em 1981 e publicada em livro dois anos mais tarde.

A feliz idéia dessa edição em língua portuguesa favorece o público brasileiro em pelo menos três direções. Em primeiro lugar, possibilita o contato mais estreito com os trabalhos desse psicossociólogo francês que, desde os anos 1980, vem discutindo o tema da sexualidade.

Doutor em Psicologia, atualmente Alain Giami é diretor do Institut National de la Santé et de la Recherche Médicale (INSERM) e professor da Universidade Paris 8. Em segundo lugar, permite conhecermos o revigoramento do interesse na França em torno da sexualidade dos deficientes mentais, frente às propostas de regulamentação da esterilização e de extensão da prevenção do HIV-Aids a esse grupo específico, apresentadas em meados dos anos 1990 em relatórios do Comité Consultatif National d'Ethique e do Conseil National du Sida. Em terceiro lugar, mas não menos importante, a publicação desse livro em nosso contexto atual propicia uma leitura interessada, tendo em vista as discussões que vêm sendo travadas no Brasil entre o campo acadêmico, os movimentos sociais e os gestores de políticas públicas em torno dos direitos reprodutivos e sexuais. Nessa perspectiva, $O$ anjo e a fera discute, respectivamente, os temas da contracepção e da homossexualidade.

A originalidade e o refinamento do livro estão em nos convidar a articular essas discussões em relação a um grupo social que expressa uma interseção 
entre saúde sexual e saúde mental. Favorece, portanto, pensarmos de que modo se instaura e se consolida o estatuto social da diferença em relação a grupos determinados, nesse caso, interconectando sexualidade e deficiência mental. A pesquisa - centrada em entrevistas semidiretivas em grupo e entrevistas nãoestruturadas individuais com pais e educadores em quatro instituições - partiu do caráter problemático atribuído por esses atores sociais à sexualidade, exatamente por referi-la a um grupo identitário marcado por uma dupla especificidade: um déficit mental e a vida em instituição.

O primeiro capítulo apresenta um ótimo relato sobre as opções teóricometodológicas feitas nas diferentes etapas da investigação, destacando as primeiras hipóteses do trabalho: a de que as relações entre os deficientes mentais e os educadores nas instituições são marcadas pela afetividade. Essa afetividade serve de base para a interação entre educadores e pais, alimentando os conflitos de representações entre eles; conflitos esses que giram em torno da "educação sexual". A idéia de representação social é central para o autor, que considera com essa noção o processo, conteúdo e orientação de condutas que se produz em função das relações sociais entre os grupos. Ao analisar a interação constante de pais e educadores - dado o fato de os pais formarem as associações que administram as instituições - o autor apresenta o modo como os grupos observam-se uns aos outros e imaginam diferencialmente suas representações sobre a sexualidade dos deficientes mentais.

Os educadores falam sobre as relações entre os sexos, as relações sexuais genitais, a masturbação, a homossexualidade masculina e o mongolismo, as condutas verbais como substitutivas das condutas sexuais e sua oposição às representações dos pais sobre o assunto, que traduzem como de negação da sexualidade dos deficientes. Para os educadores, os deficientes têm uma sexualidade, ainda que ela transite entre o extravasamento selvagem e irreprimível, e a inibição, o embotamento. Os pais, por sua vez, enfatizavam muito mais os componentes afetivos das vidas relacionais de seus próprios filhos, eternas "crianças" dessexualizadas, buscando como que uma defesa para lidar com questões como a autonomia, a gravidez e o exercício da maternidade e da paternidade pelos deficientes. Representam assim os deficientes como plenos de uma afetividade "pura" e em alguns casos muito mais desenvolvida que a das pessoas "normais"; afetividade essa que, segundo as representações dos pais, os educadores desconhecem em função do foco excessivo que concedem às relações genitais. A tematização da sexualidade, por pais e educadores, reforça as características consideradas próprias desse 
grupo identitário, opostas e complementares, ao falar tanto de um lado angelical - como uma criança a ser protegida devido ao que "falta" em sua constituição e desenvolvimento - quanto de seu lado bestial, como um monstro a eliminar (ou negar) devido a uma inadequação "excessiva" com a qual é difícil lidar.

Pais e educadores, entretanto, negociam suas representações com a realidade da vida na instituição e da vida familiar, produzindo "regulações" da sexualidade, em especial aquelas ligadas à contracepção. Nesse caso a diferença das posições entre pais e educadores se dá apenas no nível dos discursos. Enquanto os educadores utilizam um argumento pedagógico da necessidade de negociação com o deficiente sobre métodos contraceptivos, os pais não valorizam a adesão do deficiente, já que esta implica o pressuposto da responsabilidade que não poderia ser atribuída a este último. "Partindo de premissas opostas (a representação da sexualidade), pais e educadores chegam a adotar condutas convergentes na gestão da sexualidade dos deficientes, na escolha dos contraceptivos e da esterilização e na oposição à eventualidade de um bebê" (p. 119). Como anjos ou como feras, os deficientes são representados por uma alteridade fundamental que justifica o controle das relações genitais e interdita o exercício pleno da sexualidade.

O capítulo seguinte trata exatamente das diferentes organizações institucionais da sexualidade, observando como se processam as "regulações". Parte da hipótese de que essas organizações institucionais estabelecem uma distinção entre a vida sexual possível de ser gerida no meio externo e aquela que pode existir na instituição, sendo o grande divisor de águas a dissociação que a instituição estabelece entre funções eróticas e procriativas. Instituições como a família, a religião e o direito exercem influências, positivas ou negativas, sobre essas regulações.

De um lado, Alain Giami retoma os trabalhos de Erving Goffman sobre as instituições totais e de John Gagnon sobre a homossexualidade nas prisões, demonstrando as diferenças de abordagens em relação ao tema da organização institucional da sexualidade. Se as instituições totais provocam uma ruptura com a vida comunitária e produzem a separação rigorosa dos sexos, nesse contexto, a homossexualidade sintetiza aquilo que da sexualidade escapa à instituição, com o meio endógeno favorecendo a expressão de uma "tendência" individual preexistente. Já no caso das prisões, a privação súbita da heterossexualidade diminui toda forma de atividade sexual, favorecendo diversos tipos de atividades sexuais - não apenas as condutas homossexuais, mas a 
masturbação, os contatos sexuais com animais e o consumo de vídeos e revistas pornográficas - as quais são significadas de forma diversa pelos indivíduos que as praticam.

De outro lado, o autor parte dos estudos sociológicos franceses sobre a sexualidade, demonstrando a construção sócio-histórica da preeminência do modelo do casal e a defesa contemporânea de uma vida sexual saudável que reúna as funções social, erótica e procriativa. Argumenta, entretanto, que na organização institucional da sexualidade as regulações se opõem à criação do casal heterossexual e às relações potencialmente procriativas. A análise de Giami, sobre as instituições para deficientes mentais de tipo misto ou não-misto, observa semelhanças com os estudos sobre instituições totais no que se refere à existência de condutas sexuais de diferentes naturezas. Ao mesmo tempo, a introdução do regime misto nas instituições para deficientes mentais tem ajudado no reconhecimento da existência da sexualidade e em regulações mais leves que permitem acomodar os casais; um reconhecimento apenas da função erótica da sexualidade, a função reprodutiva ainda sendo alvo de interdição.

Não é à toa, portanto, que o terceiro capítulo aborda a questão da esterilização em face da sexualidade das pessoas com deficiência mental, partindo da hipótese de que a esterilização é um dos meios do controle da atividade sexual desse grupo. Para tanto, A. Giami apresenta a história da esterilização na França, demonstrando que o debate francês de meados de 1990 se fundamentou na separação entre o problema geral da esterilização e o problema das pessoas deficientes mentais, no qual a esterilização é considerada um método contraceptivo, apesar da falta de discussão sobre as condições de acesso e as formas de contracepção reversíveis (como o aborto). Giami conclui então que o tratamento específico dado à esterilização em deficientes mentais reforça o caráter de exceção concedido a essas pessoas. Esse caráter de exceção está centrado no estatuto jurídico que encerra a deficiência mental, expressando mais uma categoria jurídica e administrativa do que nosográfica. Afinal trata-se antes de tudo da questão da possibilidade de responsabilização desses sujeitos por seus atos. Nessa responsabilização, o autor destaca a diferença de gênero que se estabelece, já que, assim como na sociedade em geral, também entre os deficientes mentais a gestão reprodutiva recai sobre as mulheres. Assim a esterilização aparece como uma forma específica de regulação da sexualidade e das capacidades reprodutivas das mulheres deficientes mentais. 
O último capítulo detém-se então na discussão da esterilização de mulheres deficientes mentais e na questão do consentimento esclarecido para tal fim. Parte do contexto das discussões francesas sobre bioética para a regulamentação de procedimentos e pesquisas biomédicas, introduzindo aí o problema da tradução da noção de "consentimento livre, esclarecido e intencional" para a idéia de um consentimento dos "incapazes", tais como as pessoas deficientes mentais. Apoiado em sua pesquisa, Giami argumenta que essa questão está longe de ser resolvida e que a esterilização contraceptiva em mulheres deficientes mentais envolve negociações entre quem faz o pedido, a quem deve ser aplicado e como os pais e os educadores se posicionam frente aos casos, exercendo influência pró ou contra o consentimento "voluntário" para a esterilização.

Ao recolocar a discussão dos direitos reprodutivos e dos direitos sexuais a partir, respectivamente, dos temas da esterilização como contracepção e da homossexualidade, o livro nos remete à questão da produção de identidades sociais que resulta de considerações sobre a sexualidade. No caso dos deficientes mentais, essas considerações operam por mecanismos representacionais e institucionais que reforçam o caráter de exceção desse grupo frente à sociedade contratual. Mas também em relação às chamadas "minorias sexuais", são as considerações sobre o estatuto da diferença inscrita na sexualidade que têm situado esses grupos num lugar socialmente inferior. Assim, a partir de um mergulho profundo sobre o caso dos deficientes mentais, Giami nos leva a refletir sobre as representações sociais da sexualidade para além desse grupo específico: por intermédio de outros mecanismos - que também acionam o estigma e o argumento da patologização - o que está em jogo é a redução do exercício pleno do livre arbítrio.

\section{NOTA}

* Doutora em Antropologia Social pelo Museu Nacional/UFRJ; pesquisadora visitante na Casa de Oswaldo Cruz, com bolsa CNPq/Fiocruz e professora no Programa de Pós-Graduação em História das Ciências e da Saúde da COC/Fiocruz. Endereço eletrônico: anavenancio@coc.fiocruz.br. 